\title{
Commentary \\ The Challenge of Behaviour Change and Health Promotion
}

\author{
Glenn Laverack \\ Unit for Health Promotion Research, University of Southern Denmark, Niels Bohrs Vej 9-10, \\ DK-6700 Esjberg, Denmark; glaverack@health.sdu.dk
}

Received: 22 September 2017; Accepted: 14 October 2017; Published: 17 October 2017

\begin{abstract}
The evidence about the effectiveness of behaviour change approaches-what works and what does not work-is unclear. What we do know is that single interventions that target a specific behavioural risk have little impact on the determinants that actually cause poor health, especially for vulnerable people. This has not prevented health promoters from continuing to invest in behaviour change interventions which are widely used in a range of programs. The future of behaviour change and health promotion is through the application of a comprehensive strategy with three core components: (1) a behaviour change approach; (2) a strong policy framework that creates a supportive environment and (3) the empowerment of people to gain more control over making healthy lifestyle decisions. This will require the better planning of policy interventions and the coordination of agencies involved in behaviour change and empowerment activities at the community level, with government to help develop policy at the national level.
\end{abstract}

Keywords: behaviour change; empowerment; health promotion; inequity; policy framework

\section{Behaviour Change and Health Promotion}

The behaviour change approach promotes health through individual changes in lifestyle that are appropriate to people's settings [1]. The assumption is that, before people can change their lifestyle, they must first understand basic facts about a particular health issue, adopt key attitudes, learn a set of skills and be given access to appropriate services. The simple logic is that some behaviour leads to ill-health, and so persuading people directly to change their behaviour must be the most efficient and effective way to reduce illness. This reasoning is attractive to decision-makers because it promises quantifiable results within a short time frame, can deal with high prevalence health problems, is relatively simple and offers savings in health care services, especially for people suffering from chronic diseases [2].

The evidence about the effectiveness of behaviour change approaches is unclear, for example, about handwashing among children [3] and cooking and food skills among adults [4]. However, this has not prevented health promoters from continuing to extensively invest in this approach. Behaviour change communication is a widely-used intervention manifested through approaches such as communication for development (C4D), water, sanitation and hygiene (WASH) and social behaviour change communication. These approaches attempt to provide new knowledge and skills that people need to adopt a healthier lifestyle. They use a range of techniques including interactive communication technologies, motivation, counselling, persuasion, influencing social norms and coercion. Health promotion has also relied on pre-packaged, top-down programs especially for health education and multi-risk factor reduction interventions. These have not guaranteed a change in behaviour and has led to a "blaming of the victim", for example, for drinking too much alcohol or continuing to smoke even though people know the behaviour is harmful. This can create feelings of mistrust between "expert" practitioners and the public [5], further exasperated by changes in health messaging, for example, on the safe levels of alcohol consumption. 
Fundamentally, people do not resist change, but they do resist being changed. This is a situation made worse by health promotion programs that have an over-reliance on didactic styles of communication, inadequate audience segmentation, inappropriate message content and weak material development [6]. The art of health promotion is knowing when and how to use the science to produce a desired outcome but many practitioners lack the competence and confidence to achieve this in different contexts [7].

Behaviour change and health promotion can be made more effective and sustainable if the following elements are included (1) a strong policy framework that creates a supportive environment and (2) an enablement of people to empower themselves to make healthy lifestyle decisions.

\section{Behaviour Change and Policy Frameworks}

Despite decades of acknowledging the direct influence of poverty, unemployment and housing on people's health, the policy problems often end up being defined as a behavioural risk such as physical inactivity. We know that diseases are caused by a complex interaction of factors; in particular, those that are driven by political, social and economic determinants. The importance of a broader determinants approach is recognised in health promotion work that moves beyond the individual behavioural model. However, this requires an understanding that health is determined by how societies themselves are structured and the political nature of health policy agendas [8].

Health promotion interventions that directly address behavioural risks can, at best, support policy to promote health and, at worse, maintain inequalities in society. This is because behaviour change approaches have little impact on the broader conditions that create poor health, especially for vulnerable people such as migrants, low socio-economic and indigenous groups. Behaviour change approaches are better implemented as part of a wider, comprehensive policy framework and not as a single intervention that relies on top-down, communication strategies to target a specific disease or behaviour.

In Estonia, $89 \%$ of schoolchildren drink sugar-sweetened beverages. The Estonian government has used a policy framework to reduce the consumption of sugar-sweetened drinks which are associated with increased energy intake and higher risks for poor oral health and weight gain. The behaviour change strategy uses a policy framework with four options: (1) regulation of food advertising; (2) labelling of sugar-sweetened beverages and raising awareness about their health effects; (3) school health promotion interventions and nutrition policies; and (4) imposing taxes on sugar-sweetened beverages, subsidizing other food groups and/or substituting alternative beverages. It was concluded that these options complement each other and, if implemented in combination, would help to reach the goal of better health outcomes [9].

Comprehensive, multicomponent interventions are more appropriate to change behaviours that can lead to negative health effects. In particular, a strong policy framework is empowering because it gives people more control over their lives, rather than simply telling them what to do. Behaviour change interventions must therefore be supportive of a strong policy framework.

\section{Behaviour Change, Participation and Empowerment}

Health promotion programs are often dependent on the participation of targeted people. People also want to participate and will do so in large numbers if they are properly engaged and have a shared interest in the program. Successful participation should be congratulated; for example, the "walking for health" project recruited 8300 volunteer walk leaders [10] and the Heritage Lottery Fund [11] recruited 5900 park friends and user groups across the UK (up 1100 from the previous year). However, participation is insufficient to help people to empower themselves and to take the necessary actions to have a healthier lifestyle.

If the health promotion approach gives the practitioner the authority to control the situationfor example, through setting the agenda or releasing specific resources-it is less likely to be empowering. If it facilitates a process of needs assessment, capacity building and local action it has a much better chance of being empowering. In practice, an empowerment approach involves 
helping people to work together to gain more control over their lives and health [12] such as by organising exercise classes or self-help groups. The behaviour change approach can be paternalistic and often disregards the individual's own perception of what is important. Furthermore, the behaviour change approach can lead to stigmatization and to increased inequalities in health, as its focus is on individual behaviours instead of the "causes of the causes" of poor health. The empowerment approach does not have these problems but can lead to empowering some groups over others, as the focus is not primarily on health and empowered people might still choose to behave in ways that can damage their health because this is secondary to other personal goals. However, the empowerment approach, on the whole, has been considered to be superior to the behaviour change approach [13].

In practice the key question is: "Do I want to help others to empower themselves or to simply change their behaviour?". The added value of empowerment is that it gives the individual, group, or community greater control, in achieving healthier, sustainable lifestyles. The "Altogether Better project", for example, was established in 2008 and has engaged over 18,000 volunteers as community "health champions" who have in turn reached over 104,000 other participants. The project aims at building capacity to empower communities to improve their own health and well-being largely by extending the skills and expertise of local volunteers. The project approach has demonstrated effectiveness in supporting positive behaviour change, improving health, the use of health care services and by decreasing hospital admissions [14].

\section{The Future of Behaviour Change and Health Promotion}

In reality, the modest success of behaviour change in health promotion programs has been with those at the top of the social gradient and may even, at least temporarily, have led to an increase in health inequalities [15]. The future of behaviour change and health promotion is through the application of a comprehensive strategy to better enable people to have a healthy lifestyle. A comprehensive strategy includes the points raised in this commentary: (1) a behaviour change approach; (2) a strong policy framework that creates a supportive environment; and (3) the empowerment of people to gain more control over making healthy lifestyle decisions. A comprehensive strategy will require the better planning and coordination of policy frameworks so that they systematically include both community empowerment and behaviour change communication opportunities. The agencies involved in delivering behaviour change and empowerment interventions at the community level will have to work closely together as well as with government to help develop policy at the national level.

Conflicts of Interest: The author declare no conflict of interest.

\section{References}

1. UNDP. Communication Behaviour Change Tools. Entertainment-Education; UNICEF: New York, NY, USA, 2002; Volume 1, pp. 1-6.

2. Bernier, N. Health promotion program resilience and policy trajectories: A comparison of three provinces. In Health Promotion in Canada: Critical Perspectives; O'Neill, M., Rootman, I., Pederson, A., Dupéré, S., Eds.; Canadian Scholars' Press Inc.: Toronto, ON, Canada, 2007.

3. Watson, J. Does Targeting Children with Hygiene Promotion Messages Work? The Effect of Handwashing Promotion Targeted at Children, on Diarrhoea, Soil-Transmitted Helminth Infections and Behaviour Change, in Low- and Middle-Income Countries. Trop. Med. Int. Health 2017, 22, 526-538. [CrossRef] [PubMed]

4. Hollywood, L.; Surgenor, D.; Reicks, M.; McGowan, L.; Lavelle, F.; Spence, M.; Raats, M.; McCloat, A.; Mooney, E.; Caraher, M.; et al. Identification of behavior change techniques applied in interventions to improve cooking skills and food skills among adults. Crit. Rev. Food Sci. Nutr. 2017, 1-14. [CrossRef] [PubMed]

5. Syme, L. Individual vs. Community Interventions in Public Health Practice: Some thoughts about a New Approach. Vichealth Lett. 1997, 2, 2-9.

6. Corcoran, N. Communicating Health: Strategies for Health Promotion, 2nd ed.; SAGE Publications: London, UK, 2013. 
7. Laverack, G. The challenge of the "art and science" of health promotion. Challenges 2017, 8, 22. [CrossRef]

8. Mouy, B.; Barr, A. The social determinants of health: Is there a role for health promotion foundations? Health Promot. J. Aust. 2006, 17, 189-195.

9. Köhler, K.; Eksin, M.; Peil, E.; Sammel, A.; Uuetoa, M.; Villa, I. Policy Brief: Reducing the Consumption of Sugar-Sweetened Beverages in Estonia (World Health Organization EVIPNet Initiative); World Health Organization Regional Office for Europe: Copenhagen, Denmark, 2016.

10. Walking for Health. Available online: https:/ / www.walkingforhealth.org.uk/ (accessed on 15 September 2017).

11. Heritage Lottery Fund. State of UK Public Parks-2016; Heritage Lottery Fund: London, UK, 2016.

12. Werner, D. Empowerment and Health: Contact; Christian Medical Commission: Geneva, Switzerland, 1988; Volume 102, pp. 1-9.

13. Tengland, P. Behavior change or empowerment: On the ethics of health promotion goals. Health Care Anal. 2016, 24, 24-46. [CrossRef] [PubMed]

14. Altogether Better. Working with Citizens and Services to Improve Health. Available online: http://www. altogetherbetter.org.uk (accessed on 15 September 2017).

15. Baum, F. Cracking the nut of health equity: Top down and bottom up pressure for action on the social determinants of health. Promot. Educ. 2007, 14, 90-95. [CrossRef] [PubMed]

(C) 2017 by the author. Licensee MDPI, Basel, Switzerland. This article is an open access article distributed under the terms and conditions of the Creative Commons Attribution (CC BY) license (http:/ / creativecommons.org/licenses/by/4.0/). 